\title{
VALIDATION OF HEPATOPROTECTIVE USE OF POLYGONUM PERFOLIATUM EXTRACT AGAINST PARACETAMOL INDUCED TOXICITY IN WISTAR RATS
}

\author{
MOHAMMAD SALEEM ${ }^{1 *}$, MUHAMMAD FAHD MUSHTAQ ${ }^{2,6}$, \\ MUHAMMAD FURQAN AKHTAR ${ }^{3}$, AMMARA SALEEM ${ }^{2}$, SARA ZAHID ${ }^{4}$, ALI SHARIF ${ }^{4}$, \\ BUSHRA AKHTAR $^{5}$, ESHWA DAR ${ }^{6}$, MUNAIR BADSHAH ${ }^{7}$ and MAJEED ULLAH ${ }^{8}$
}

${ }^{1}$ Department of Pharmacology, University College of Pharmacy, University of the Punjab, Lahore, Pakistan ${ }^{2}$ Department of Pharmacology, Faculty of Pharmaceutical Sciences,

Government College University Faisalabad, Faisalabad, Pakistan

${ }^{3}$ Riphah Institute of Pharmaceutical Sciences, Riphah International University,

Lahore Campus, Lahore, Pakistan

${ }^{4}$ Faculty of Pharmacy, The University of Lahore, Lahore, Pakistan

${ }^{5}$ Institute of Pharmacy, Physiology, and Pharmacology, University of Agriculture,

Faisalabad, Pakistan

${ }^{6}$ Islam College of Pharmacy, Sialkot, Pakistan

${ }^{7}$ Department of Pharmacy, COMSATS institute of Information Technology,

Abbottabad, 22060, Pakistan

${ }^{8}$ Department of Pharmacy, Kohat University of Science and Technology, Kohat, 26000, Pakistan

\begin{abstract}
The liver as a vital body organ is adversely affected by hazardous chemicals and drugs. Paracetamol widely used asan analgesic and antipyretic drug produces severe hepatotoxicity at high doses. Present study was designed to investigate the hepatoprotective activity of Polygonum perfoliatum L. used on folklore basis. Aqueous methanolic extract of the plant was prepared. Preliminary phytochemical and HPLC analyses were carried out to identify and quantify chemical constituents respectively. For hepatoprotective activity, Wistar rats were divided into six groups as normal control, standard (silymarin) control, negative control and extract treated groups i.e., 125, 250 and $500 \mathrm{mg} / \mathrm{kg}$ /day per oral. Paracetamol was administered orally, following seven days of previously stated therapy. Biochemical parameters of hepatotoxicity such as serum glutamic pyruvate transaminase (SGPT), serum glutamic oxaloacetate transaminase (SGOT), alkaline phosphatase (ALP) and total bilirubin were measured in all groups. Histopathological evaluation of liver was also carried out. Benzoic acid, chlorogenic acid, gallic acid, m-coumaric acid, quercetin, and vitamin E were detected in the plant extract through HPLC. The hepatoprotective effect of $500 \mathrm{mg} / \mathrm{kg} /$ day therapy was more pronounced than 125 and 250 $\mathrm{mg} / \mathrm{kg}$ dose. However, the effect of plant extract was less pronounced than standard silymarin therapy. It can be concluded that the plant extract possessed significant hepatoprotective activity that may be attributed to quercetin, benzoic acid, gallic acid and vitamin E present in it.
\end{abstract}

Keywords: hepatoprotective, hepatotoxicity, paracetamol, vitamin E, quercetin, HPLC

The liver is a vital body organ that metabolizes carbohydrates, lipids, proteins, and bilirubin. It also contributes to the immune system and blood coagulation process. Viral and non-viral liver diseases are notable causes of morbidity and mortality all over the world, especially in low and middle-income countries. Synthetic and natural chemicals, drugs, herbal remedies, and environmental pollutants exert detrimental toxic effect on the liver and are termed as hepatotoxins (1). Toxicants impair the function of mitochondria and other organelles involved in energy production and alter the function of antioxidant enzymes resulting in oxidative stress that damages hepatocytes (2).

Medicinal plants have played an imperative role in human health for several thousand years (3).

\footnotetext{
* Corresponding author: e-mail: msaleem0141@hotmail.com, saleem2978@hotmail.com
} 
Pharmacological and toxicological characteristics of medicinal plants are attributed to the occurrence of various phytochemicals in these plants (4). Several medicinal plants such as Allium hirtifolium, Apium graveolens, Phyllanthus niruri, Cosmos sulphureus, and Cynara scolymus have been validated for their ethnomedicinal potential as hepatoprotective agents (5). However, ethnic use of the most plants of Asia and Africa lack scientific validation and pharmacological relevance (6).

The plant, Polygonum perfoliatum L. (family: Polygonaceae) is commonly known as Devil's-tail. It is an annual vine that has been used in Chinese medicine for more than three centuries (7). It is indigenous to Asia and widely distributed in South and South East Asia. It is considered an invasive herb in the United States (8). It is traditionally used as diuretic, anti-inflammatory, anti-diabetic and hepatoprotective agent. It has been pharmacologically validated for its antiviral, anti-inflammatory, antitumor and anti-bacterial activities (9). Terpenoids, phenylpropanoids, 8-oxo-pinoresinol, quercetin-3-O- $\beta$-D-glucuronide, flavonoids, and volatile oils have been isolated from the plant (10).

Allopathic medicinal system lacks efficacious, safe and cost-effective hepatoprotective drugs (11). It necessitates the development of novel natural or synthetic drugs for the prevention and treatment of hepatic disorders. The plant P. perfoliatum may have potential hepatoprotective activity due to its antioxidant characteristics and presence of phenolic and flavonoids (12). Therefore, the current study was designed to investigate the hepatoprotective action of $P$. perfoliatum against paracetamol-induced intoxication.

\section{EXPERIMENTAL}

\section{Collection of plant and preparation of extract}

The whole plant of $P$. perfoliatum was collected from the rural areas of District Bagh, Azad Jammu and Kashmir. The plant was identified and verified taxonomically. The plant sample was deposited in the herbarium of Government College University, Lahore, Pakistan under voucher specimen (GC.Herb.Bot.2951) for future reference. The whole plant was thoroughly washed with water, dried under shade and grounded to a coarse powder with the help of mechanical grinder. The powder was soaked in aqueous methanolic $(70: 30)$ solution for seven days and shaken periodically. The procedure was repeated thrice. The filtrate was collected and pooled. Rotary evaporator was used to concentrate the extract (brownish jelly paste) at low temperature $\left(40-45^{\circ} \mathrm{C}\right)$. The extract was transferred to amber colored bottles and stored in a refrigerator until further use.

\section{Preliminary phytochemical screening}

Aqueous methanolic extract was evaluated for the presence of different primary and secondary metabolites. The detection tests for flavonoids, alkaloids, tannins, saponins, resins, coumarins and terpenoids were performed according to the previous standard methods (13).

\section{Quantification of phytochemicals}

Quercetin and other phytochemicals such as gallic acid, benzoic acid and vitamin E were identified and quantified in aqueous methanolic extract by HPLC. The plant extract was dissolved in $60 \%$

Table1. List of chemical phytochemical constituents and their identification.

\begin{tabular}{|c|c|c|c|}
\hline $\begin{array}{l}\text { Chemical } \\
\text { constituents }\end{array}$ & Procedure & Observations & Result \\
\hline Alkaloids & $\begin{array}{l}0.4 \mathrm{~g} \text { powder dissolved in } 1 \% \mathrm{HCl} \text {, heated for } 2-3 \mathrm{~min} \text {, filtered } \\
\text { and treated with Dragendorff's reagent }\end{array}$ & $\begin{array}{l}\text { Orange } \\
\text { reddish ppt. }\end{array}$ & Positive \\
\hline Flavonoids & $\begin{array}{l}\text { Solution A and B from plant extract were prepared. Solution A } \\
\text { contained } 4 \mathrm{~mL} \text { methanolic plant extract. The B solution contained } \\
6 \mathrm{~mL} \text { ethanolic solvent and } 4 \mathrm{~mL} 50 \% \mathrm{KOH} \text { was added to it, } \\
\text { followed by mixing of A and B solutions }\end{array}$ & Yellow color & Positive \\
\hline Coumarins & $\begin{array}{l}3 \mathrm{~mL} \text { plant extract was added to test tube, covered with } \mathrm{NaOH} \\
\text { treated filter paper and boiled for } 10 \mathrm{~min} \text { in water bath followed } \\
\text { by filter paper exposure to ultraviolet light }\end{array}$ & $\begin{array}{l}\text { Bright green } \\
\text { yellow color }\end{array}$ & Positive \\
\hline Resins & $4 \mathrm{~mL}$ extract of plant was taken and $3 \mathrm{~mL} \mathrm{HCl}(4 \%)$ was added to it & Turbidity & Negative \\
\hline Tannins & $2-3$ drops of $1 \% \mathrm{FeCl} 3$ were added to $4 \mathrm{~mL}$ plant extract & Blue color & Positive \\
\hline Terpenoids & $\begin{array}{l}2 \mathrm{~mL} \text { sulfuric acid and } 3 \mathrm{~mL} \text { acetic anhydride were added to } 2 \mathrm{~mL} \\
\text { plant extract }\end{array}$ & $\begin{array}{l}\text { Reddish brown } \\
\text { color interface }\end{array}$ & Positive \\
\hline
\end{tabular}


Table 2. Phytochemicals in HPLC analysis of Polygonum perfoliatum.

\begin{tabular}{|c|c|c|c|c|c|c|}
\hline Compounds & $\begin{array}{c}\text { Retention } \\
\text { time }(\mathrm{min})\end{array}$ & $\begin{array}{c}\text { Area } \\
(\mathrm{mV} . \mathrm{s})\end{array}$ & $\begin{array}{c}\text { Height } \\
(\mathrm{mV})\end{array}$ & $\begin{array}{c}\text { Percentage } \\
\text { of area }\end{array}$ & $\begin{array}{c}\text { Percentage } \\
\text { of height }\end{array}$ & $\begin{array}{c}\text { Quantity } \\
(\mathrm{ppm})\end{array}$ \\
\hline Quercetin & 2.907 & 10.386 & 1.151 & 0.4 & 3.4 & 0.54 \\
\hline Vitamin E & 3.827 & 2627.098 & 34.0 & 0.000 & 0.0 & 814.37 \\
\hline Gallic acid & 4.333 & 129.418 & 3.478 & 5.1 & 10.3 & 4.48 \\
\hline Benzoic acid & 14.207 & 15.056 & 0.379 & 0.6 & 1.1 & 1.59 \\
\hline Chlorogenic acid & 15.273 & 15.068 & 0.373 & 0.6 & 1.1 & 1.17 \\
\hline m-Coumaric acid & 19.787 & 616.832 & 1.634 & 24.4 & 4.8 & 7.38 \\
\hline
\end{tabular}

methanol solution. The sample was prepared by acid hydrolysis and injected into HPLC after filtration through $0.2 \mu \mathrm{m}$ syringe filter. The mobile phase comprised of water, acetic acid and acetonitrile. The mobile phase used for identification of Vitamin $\mathrm{E}$ and phytochemicals was methanol at $0.5 \mathrm{~mL} / \mathrm{min}$ flow rate in a C18 column at 280 and $295 \mathrm{~nm}$ wavelength respectively (5).

\section{Experimental animals}

The hepatoprotective study was performed on albino Wistar rats of 200-250 g. The animals were provided free access to standard chow diet and fresh water. Animals were kept in steel cages of Animal House of Government College University Faisalabad under standard laboratory temperature $25 \pm$ $2^{\circ} \mathrm{C}$ in a $12 \mathrm{~h}$ cycle of light and dark.

\section{Experimental protocol}

In the current study, rats of both sexes were randomly divided into groups of six animals. Group 1 was considered as normal control and received fresh water only. Group 2 was untreated disease control. Group 3 was the reference control group treated with standard drug silymarin $50 \mathrm{mg} / \mathrm{kg} / \mathrm{day}$ for 7 days. Group 4, 5 and 6 were administered 125 , 250 and $500 \mathrm{mg} / \mathrm{kg} /$ day plant extract respectively for 7 days. All the therapies were administered orally. $500 \mathrm{mg} / \mathrm{kg}$ paracetamol was administered orally to all groups $3 \mathrm{~h}$ post-administration of daily therapy on day 7 , except group 1 . The animals were anesthetized $24 \mathrm{~h}$ post paracetamol ingestion and blood was collected by heart puncture (5).

\section{Biochemical investigation}

Serum was separated from blood by centrifugation at $4000 \mathrm{rpm}$ for $20 \mathrm{~min}$. The serum was used to evaluate the level of SGPT, SGOT, ALP, total bilirubin and total protein according to the methods described previously (14).

\section{Histopathological study}

Livers of untreated and treated rats were removed for histopathological study and stored in $10 \%$ formaldehyde solution. Staining of paraffinembedded liver tissue slices was carried out with acidic (eosin) and basic (hematoxylin) dyes. Tissue slides were seen under a light microscope for any histological abnormality (15).

\section{Statistical analysis}

The experimental data were shown as mean and standard deviation. Statistical analysis was carried out by one way ANOVA followed by post hoc test using GraphPad Prism ${ }^{\circledR}$ software version 6.0.

\section{RESULTS}

Preliminary evaluation of aqueous methanolic extract showed the presence of different primary and secondary metabolites. HPLC analysis showed the quantity of phenolic and flavonoid compounds. The plant extract also showed a decrease in serum biomarkers of liver toxicity and prevented paracetamol induced pathological changes in the liver.

\section{Screening of phytochemical constituents}

A phytochemical evaluation showed the presence of alkaloids, flavonoids, coumarins, tannins and terpenoids. Phytochemical constituents detected in the plant extract are detailed in Table 1.

\section{Quantification of phytochemicals}

Benzoic acid, chlorogenic acid, gallic acid, $m$ coumaric acid, quercetin, and vitamin $\mathrm{E}$ were found in HPLC analysis. Vitamin E was the most abundant phytochemical followed by $m$-coumaric acid. Retention time, height, percent area and quantity of detected phytochemicals are shown in Table 2 . HPLC spectrum of the plant extract is shown in Figure 1. 


\section{Biochemical evaluation}

The level of SGPT in normal control group was lower than that of paracetamol treated disease control group. However, rats pretreated with silymarin showed significantly lower level of SGPT than disease control. Rats treated with the plant extract also showed significant decrease in SGPT compared to disease control. It was also found that the level of SGOT in normal control rats was lower than paracetamol treated rats. The treatment with silymarin or plant extracts (125 or $250 \mathrm{mg} / \mathrm{kg}$ ) significantly reduced SGOT level than the disease control group. Treatment with $500 \mathrm{mg} / \mathrm{kg}$ plant extract alleviated the level of SGOT compared to standard control group as shown in Table 2.

The level of ALP increased significantly upon paracetamol exposure. However, preventive therapy with silymarin or plant extract significantly reduced the level of ALP following exposure to paracetamol. The plant extract normalized the level of ALP at

Table 3. Effect of pre-treatment with the plant extract on liver biomarkers of paracetamol treated rats.

\begin{tabular}{|c|c|c|c|c|}
\hline Experimental groups & SGPT (IU/L) & SGOT (IU/L) & ALP (IU/L) & Total bilirubin (g/dL) \\
\hline Normal control & $42.6 \pm 1.96^{* *}$ & $66.92 \pm 2.21^{* *}$ & $170.9 \pm 14.1^{*}$ & $0.28 \pm 0.03^{*}$ \\
\hline Disease control & $197.2 \pm 13.2$ & $873.3 \pm 26.8$ & $402.9 \pm 21.2$ & $0.58 \pm 0.08$ \\
\hline $\begin{array}{c}\text { Silymarin control } \\
50 \mathrm{mg} / \mathrm{kg} / \mathrm{day}\end{array}$ & $54.03 \pm 4.37^{* *}$ & $74.54 \pm 8.83^{* *}$ & $232.8 \pm 37.82^{*}$ & $0.18 \pm 0.04^{*}$ \\
\hline Extract $125 \mathrm{mg} / \mathrm{kg} /$ day & $72.51 \pm 3.97^{* *}$ & $173.5 \pm 9.51^{* *}$ & $272.8 \pm 18.1^{*}$ & $0.20 \pm 0.03^{*}$ \\
\hline Extract $250 \mathrm{mg} / \mathrm{kg} /$ day & $75.3 \pm 9.26^{*}$ & $128.8 \pm 16.3 * *$ & $232.4 \pm 17.9^{*}$ & $0.26 \pm 0.04^{*}$ \\
\hline Extract $500 \mathrm{mg} / \mathrm{kg} /$ day & $36.7 \pm 4.73^{* *}$ & $90.62 \pm 7.10^{* *}$ & $149.8 \pm 9.27^{*}$ & $0.20 \pm 0.03^{*}$ \\
\hline
\end{tabular}

Where ** showed statistically different to disease control group at $\mathrm{p}<0.01$ and $*$ showed statistically different to disease control at $\mathrm{p}<0.05$

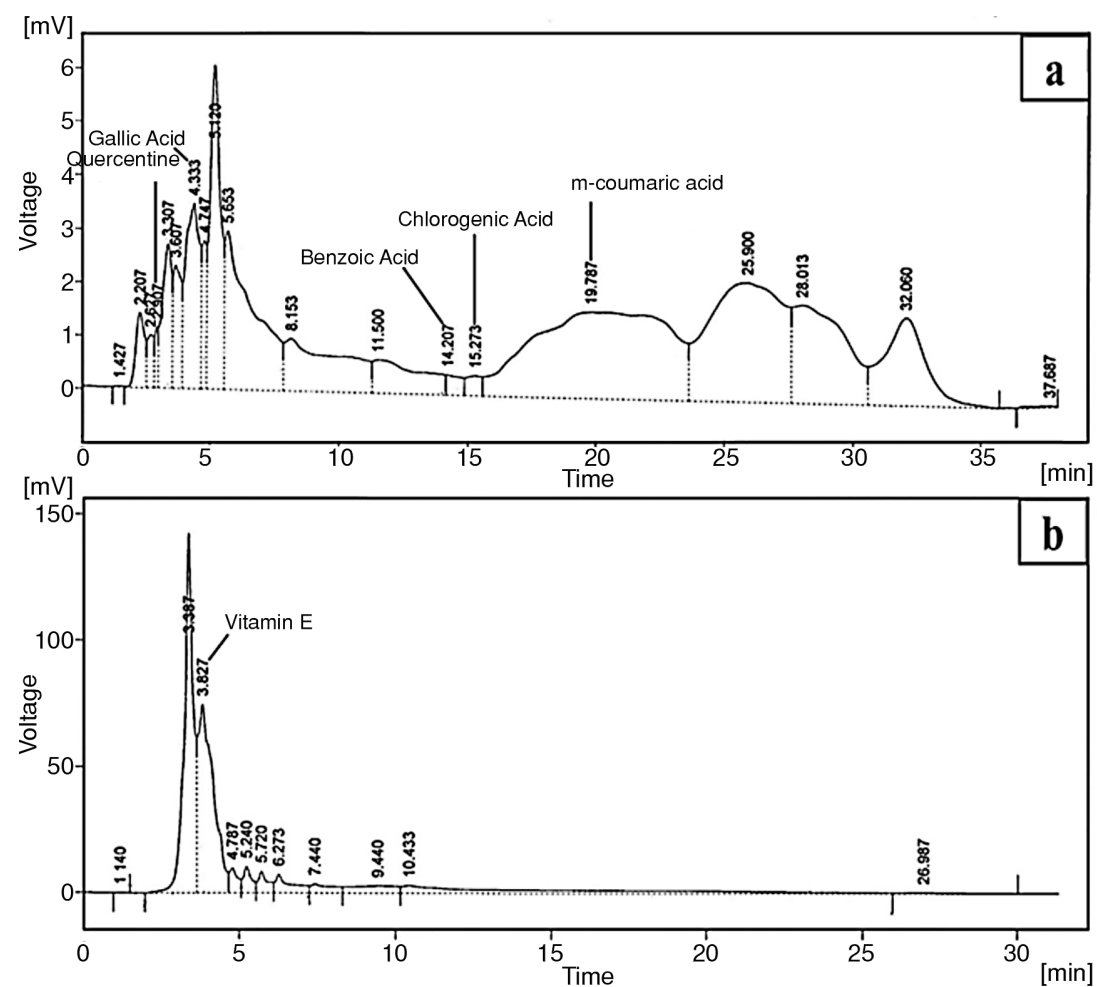

Figure 1a, b. HPLC chromatograph of the different constituents present in the aqueous methanolic extract of Polygonum perfoliatum 
Table 4. Histopathological examination (scoring) of treated and untreated rat livers.

\begin{tabular}{|c|c|c|c|c|c|}
\hline $\begin{array}{c}\text { Experimental } \\
\text { groups }\end{array}$ & Inflammation & $\begin{array}{c}\text { Simple } \\
\text { necrosis }\end{array}$ & $\begin{array}{c}\text { Hemorrhagic } \\
\text { necrosis }\end{array}$ & $\begin{array}{c}\text { Central vein } \\
\text { congestion }\end{array}$ & $\begin{array}{c}\text { Congestion of } \\
\text { sinusoidal spaces }\end{array}$ \\
\hline Normal Control & 0 & 0 & 0 & 1 & 1 \\
\hline Disease control & 1 & 1 & 1 & 1 & 0 \\
\hline Silymarin treated & 0 & 0 & 0 & 1 & 1 \\
\hline Extract $125 \mathrm{mg} / \mathrm{kg}$ & 1 & 1 & 0 & 1 & 1 \\
\hline Extract $250 \mathrm{mg} / \mathrm{kg}$ & 1 & 1 & 0 & 1 & 0 \\
\hline Extract $500 \mathrm{mg} / \mathrm{kg}$ & 0 & 0 & 0 & 1 & 1 \\
\hline
\end{tabular}

Where " 0 " showed absence and "1" showed presence of the pathological condition

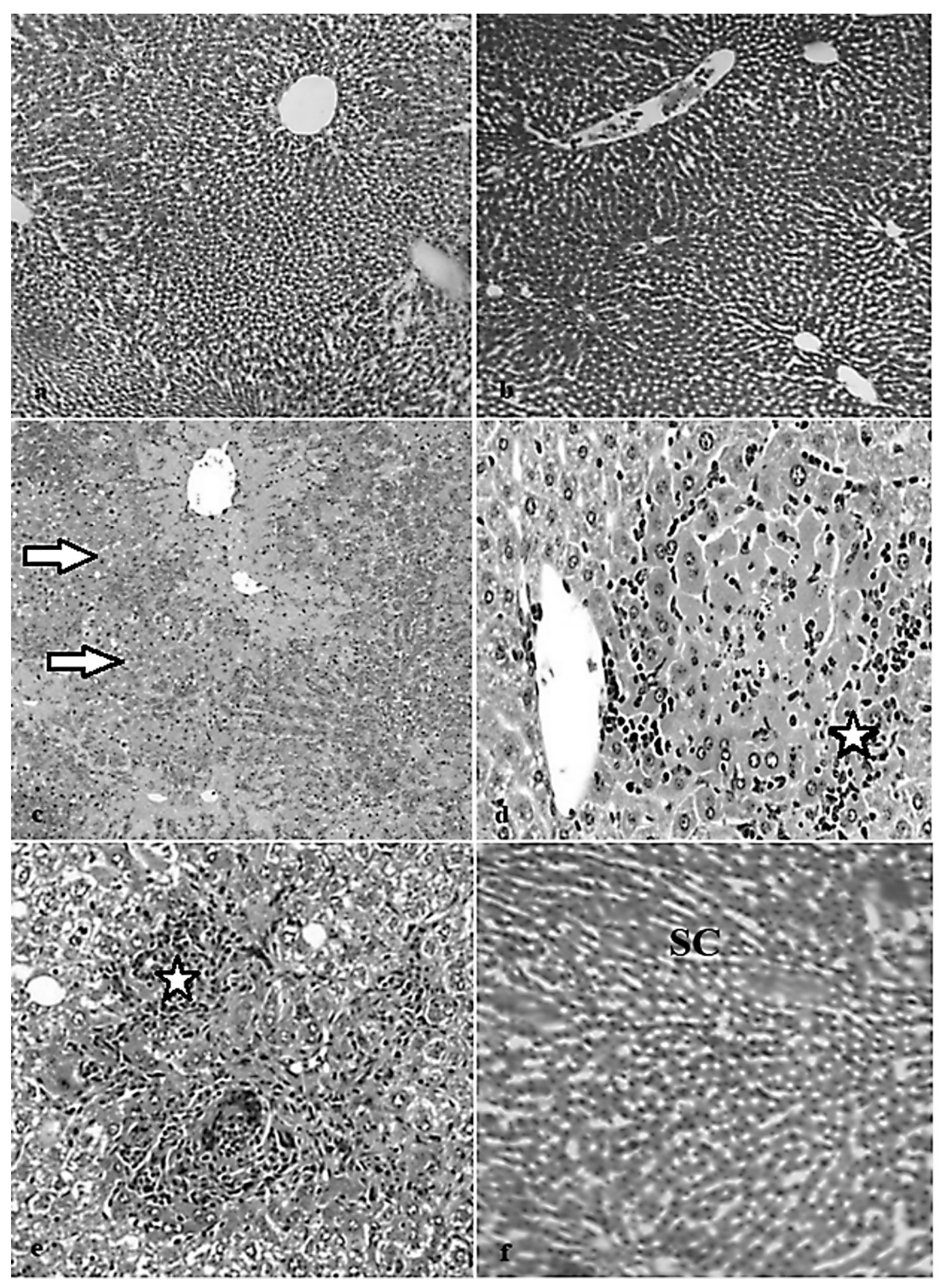

Figure 2. Histopathological photomicrographs of the treated and untreated rats. Here a, b, c, d, e, and f showed rat livers of normal control, silymarin treated, disease control, and plant extract 125, 250 and $500 \mathrm{mg} / \mathrm{kg} /$ day treated respectively. Where; star, arrow and CS showed inflammation, necrosis and sinusoidal congestion respectively 
$500 \mathrm{mg} / \mathrm{kg} /$ day dose in rats. Administration of paracetamol resulted in a rise of bilirubin. Silymarin or extract treated rats showed a significant decrease in total bilirubin compared to paracetamol treated group (Table 3 ).

\section{Histopathological study}

Histopathological findings of the liver treated with the plant extract are shown in Figure 1; histopathological scores of the control and treated rat livers are shown in Table 4. Histopathological evaluation of normal control rats revealed normal liver histology. However, disease control rats showed inflammation and, simple and hemorrhagic necrosis. Sinusoidal spaces were not enlarged. Pretreatment with silymarin for 7 days prevented hepatocellular inflammation and necrosis. Pretreatment with the plant extract also prevented hepatocellular necrosis and inflammation in a dose-dependent manner. Histopathological study of the liver showed that hepatoprotective effect of silymarin was more pronounced than therapy with the plant extract at $500 \mathrm{mg} / \mathrm{kg} /$ day. Histopathological findings of the liver treated with the plant extract are shown in Figure 2. Histopathological scores of the control and treated rat livers are shown in Table 4.

\section{DISCUSSION}

Drug-induced hepatotoxicity is a regulatory and clinical challenge. Current study validated the hepatoprotective activity of the aqueous methanolic extract of $P$. perfoliatum which has not yet been reported in the literature. HPLC analysis revealed the presence of phenolic and flavonoid compounds and Vitamin $\mathrm{E}$ in the extract. The use of extract prevented the paracetamol-induced hepatotoxicity in animals.

Paracetamol has been widely used as a model drug for induction of hepatotoxicity (16). Paracetamol often causes apoptosis of hepatocytes at high doses, in susceptible individuals and/ or those concurrently consuming alcohol (17). It is metabolized by cytochrome P450 system into $\mathrm{N}$ Acetyl-p-benzoquinone imine (NAPQI) that is detoxified by glucuronidation and sulfation. Paracetamol, when consumed in excess, produces a large amount of NAPQI that binds irreversibly to sulfhydryl ( $\mathrm{SH}$ ) group of the liver proteins and causes hepatotoxicity (18). Normally, SGPT, SGOT, ALP, and bilirubin are present in the cytoplasm of hepatocytes. Necrosis or altered membrane permeability of hepatocytes elevates the level of these hepatotoxicity biomarkers in blood (19).
In the current study, there was a significant difference between the extract treated, paracetamol treated and normal control group. The plant was evaluated for the hepatoprotective activity in experimental rats. Pre-treatment with aqueous methanolic extract of $P$. perfoliatum reduced the level of SGPT, SGOT, ALP and bilirubin at 125, 250 and 500 $\mathrm{mg} / \mathrm{kg}$ dose compared to paracetamol treated group. The reduction in hepatotoxicity biomarkers by the plant extract was less significant than the silymarin treated group. In the current study, there was a reduction in the amount of hepatotoxicity biomarkers in rats pre-treated with the plant extract probably due to the presence of flavonoids, phenolic acids and vitamin E (20).

The phytochemical constituents quantified by using HPLC analysis revealed quercetin, gallic acid, chlorogenic acid, m-coumaric acid, and benzoic acid. It is shown previously that flavonoid and phenolic compounds such as quercetin, gallic acid, chlorogenic acid, and benzoic acid are associated with the hepatoprotective effect of medicinal plants (21). Quercetin was previously reported in other species of Polygonum Genera (22). Furthermore, quercetin has shown anti-mutagenic and antioxidant effect. Antioxidant property of quercetin contributes to the hepatoprotective potential via reduction of oxidative stress (23). Benzoic acid also has pronounced hepatoprotective and antioxidant effect (24). Tung et al. reported the hepatoprotective and antioxidant properties of gallic acid (25). It is found that the use of vitamin $\mathrm{E}$ ameliorates the antioxidant enzymes in the liver to prevent the toxic effect of oxidants (26). Furthermore, it inhibits the lipid peroxidation and thus acts as an efficient antioxidant (15). Other species of the genus Polygonum such as P. multiflorum and $P$. glabrum have also shown hepatoprotective effects against carbon tetrachloride toxicity (27). On the basis of these studies, it can be assumed that the hepatoprotective potential of $P$. perfoliatum may be attributed to the presence of flavonoids such as quercetin, phenolic compounds such as benzoic acid and gallic acid and vitamin E.

The results obtained in the current study showed that the aqueous methanolic extract of $P$. perfoliatum might have hepatoprotective potential against paracetamol-induced hepatotoxicity. The hepatoprotective effect of the plant extract was most pronounced at $500 \mathrm{mg} / \mathrm{kg}$ dose. It can also be concluded that the presence of the quercetin, benzoic acid, gallic acid, and vitamin E could have contributed to the hepatoprotective effects of the plant extract. 


\section{REFERENCES}

1. Akhtar M.F., Rabbani M., Sharif A., Akhtar B., Saleem A., Murtaza G.: Afr. J. Tradit. Complement. Altern. Med. 8, 3 (2011).

2. Dyson J.K., Hutchinson J., Harrison L., Rotimi O., Tiniakos D., Foster G.R.: J. Hepatol. 64, 1 (2016).

3. Akhtar M.F., Sharif A., Saleem M., Saleem A., Akhtar B., Raza M.: Cell. Mol. Biol. 63, 8 (2017).

4. Sharif A., Akhtar M.F., Akhtar B., Saleem A., Manan M., Shabbir M.: EXCLI J. 16, 593 (2017).

5. Saleem M., Ali H.A., Akhtar M.F., Saleem U., Saleem A., Irshad I.: Nat. Prod. Res. 67, 1 (2018).

6. Akhtar M.F., Saleem A., Sharif A., Akhtar B., Nasim M.B., Peerzada S.: EXCLI J. 15, 589 (2016).

7. Jin S., Guo X., Zhang Y., Li P., He P. et al.: Chin. J. Chem. 27, 4 (2009).

8. Kumar V., DiTommaso A.: Weed Technol. 19, 4 (2005).

9. Fan D., Zhou X., Zhao C., Chen H., Zhao Y., Gong X.: Fitoterapia 82, 6 (2011).

10. Sun X., Zimmermann M.L., Campagne J.M., Sneden A.T.: J. Nat. Prod. 63, 8 (2000).

11. Saleem A., Akhtar M.F., Mushtaq M.F., Saleem M., Muhammad S.T., Akhtar B.: EXCLI J. 15, 578 (2016).

12. Granica S., Czerwińska M.E., ŻyżyńskaGranica B., Kiss A.K.: Fitoterapia 91, 180 (2013).

13. Ahmed S., Saeed-Ul-Hassan S., Islam M., Qureshi F., Waheed I., Munawar I. et al.: Acta Pol. Pharm. 74, 1 (2017).
14. Dash D.K., Yeligar V.C., Nayak S.S., Ghosh T., Rajalingam R., Sengupta P.: Trop. J. Pharm. Res. 6, 3 (2007).

15. Sharif A., Ashraf M., Javeed A., Anjum A.A., Akhtar M.F., Akhtar B.: Environ. Sci. Pollut. Res. 23, 24158 (2016).

16. Lee W.M.: N. Engl. J. Med. 349, 5 (2003).

17. Malar H.V., Bai S.M.: Afr. J. Basic. Appl. Sci. 1, 1 (2009).

18. Hurkadale P.J., Shelar P.A., Palled S.G., Mandavkar Y.D., Khedkar A.S.: Asian Pac. J. Trop. Biomed. 2, 1 (2012).

19. Gupta C., Vikram A., Tripathi D., Ramarao P., Jena G.: Phytother. Res. 24, 1 (2010).

20. Singh B., Chandan B., Sharma N., Bhardwaj V., Satti N., Gupta V.: Phytother. Res. 20, 10 (2006).

21. Chen J., Shi Y.: J. Chinese Materia Medica 34, 4 (2009).

22. Abo-Salem O.M., Abd-Ellah M.F., Ghonaim M.M.: J. Biochem. Mol. Toxicol. 25, 6 (2011).

23. Gupta A.K., Chitme H., Dass S.K., Misra N.: J Pharmacol. Toxicol. 5, 7 (2010).

24. Saravanan N., Rajasankar S., Nalini N.: J. Pharm. Pharmacol. 59, 3 (2007).

25. Tung Y.T., Wu J.H., Huang C.C., Peng H.C., Chen Y.L., Yang S.C. et al.: Food Chem. Toxicol. 47, 6 (2009).

26. Aboul-Soud M.A., Al-Othman A.M., ElDesoky G.E., Al-Othman Z.A., Yusuf K. et al.: J. Toxicol. Sci. 36, 3 (2011).

27. Lee B.H., Huang Y.Y., Duh P.D., Wu S.C.: Pharm. Biol. 50, 3 (2012).

Received: 3.05 .2018 